\title{
Expression of miR-210 in relation to other measures of hypoxia and prediction of benefit from hypoxia modification in patients with bladder cancer
}

\author{
J J Irlam-Jones ${ }^{1}$, A Eustace ${ }^{1}$, H Denley ${ }^{2}$, A Choudhury ${ }^{3}$, A L Harris ${ }^{4}$, P J Hoskin ${ }^{5}$ and C M L West ${ }^{\star}, 1$ \\ ${ }^{1}$ Translational Radiobiology Group, Institute of Cancer Sciences, University of Manchester, Manchester Academic Health Centre, \\ Manchester M20 4BX, UK; ${ }^{2}$ Department of Histopathology, Central Manchester University Hospitals NHS Foundation Trust, \\ Manchester Royal Infirmary, Oxford Road, Manchester M13 9WL, UK; ${ }^{3}$ Christie Hospital, Wilmslow Road, Manchester M20 4BX, \\ UK; ${ }^{4}$ Molecular Oncology Laboratories, Department of Oncology, Weatherall Institute of Molecular Medicine, John Radcliffe \\ Hospital, Oxford University, Oxford OX3 9DS, UK and ${ }^{5}$ Cancer Centre, Mount Vernon Hospital, Rickmansworth Road, Northwood, \\ Middlesex HA6 2RN, UK
}

Background: The addition of hypoxia modifiers carbogen and nicotinamide (CON) to radiotherapy (RT) improved overall survival (OS) in bladder cancer patients in the BCON phase III clinical trial. We investigate whether expression of hsa-miR-210 in BCON patient samples reflects hypoxia and predicts benefit from hypoxia modification.

Methods: In all, 183 T1-T4a bladder cancer samples were available for miR-210 analysis. A total of 86 received RT + CON and 97 received RT alone. TaqMan qPCR plates were used to assess miR-210 expression. Patients were classified as low $(<\mathrm{median}$ expression) or high ( $\geqslant$ median) miR-210. Data on other hypoxia biomarkers were available for comparison.

Results: Patients with high miR-210 had a trend towards improved 5-year OS with RT + CON (53.2\%) compared with RT alone (37.8\%; hazard ratio $(\mathrm{HR}) 1.68,95 \% \mathrm{Cl} 0.95-2.95, P=0.07)$. No benefit was seen with low miR-210 (HR 1.02, 95\% Cl 0.58-1.79, $P=0.97)$. High miR-210 was significantly associated with high HIF-1 $\alpha$ protein $(P=0.001), C A 9$ protein $(P=0.0004), G l u t-1$ protein $(P=0.001)$, 26-gene hypoxia score $(P=0.007)$, tumour necrosis $(P=0.02)$ and concurrent $\mathrm{pT}$ is $(P=0.03)$.

Conclusions: High miR-210 may reflect hypoxia in bladder cancer. However, its ability to predict benefit from hypoxia modification does not improve upon other hypoxia markers. Investigation as part of a miRNA hypoxia signature may reveal the full potential of miR-210.

Muscle invasive bladder cancer has a 5-year overall survival (OS) rate of around $50 \%$ despite aggressive management (Kim et al, 2000). Conventional treatment involves radical cystectomy or bladder sparing radiotherapy (RT). The BCON phase III clinical trial showed that addition of hypoxia modifiers carbogen and nicotinamide (CON) to RT improved OS (Hoskin et al, 2010). Other trials have also shown that patients benefit from fluorouracil
(5-FU) and mitomycin C (James et al, 2012) or gemcitabine (Choudhury et al, 2011). Given the variety of concurrent treatments to add to RT, there is a need for a biomarker to identify patients most likely to benefit from CON. Tumour hypoxia is associated with a poor prognosis in bladder cancer (Hoskin et al, 2003; Palit et al, 2005; Ord et al, 2007; Eustace et al, 2013a; Hunter et al, 2014). Studies suggest that those with the most hypoxic

*Correspondence: Professor CML West; E-mail: catharine.west@manchester.ac.uk

Received 31 March 2016; revised 10 June 2016; accepted 15 June 2016; published online 21 July 2016

(c) 2016 Cancer Research UK. All rights reserved 0007 - 0920/16

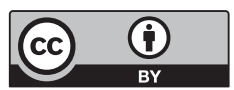

$\underset{\text { OPEN }}{\mathrm{B}} \mathrm{C}$ 
tumours are most likely to benefit (Eustace et al, 2013a; Hunter et al, 2014).

MicroRNAs (miRs) are small non-coding sequences of RNA that regulate the production of cellular proteins by either inhibiting mRNA translation, or promoting its degradation. Unlike other RNA types, miRs are not vulnerable to deterioration in formalinfixed paraffin-embedded (FFPE) samples (Hall et al, 2012), and their expression is robust and tightly controlled. There have been many studies showing hypoxia modulation of miRs (Camps et al, 2008; Huang et al, 2009; Gee et al, 2010; Babar et al, 2011; Bruning et al, 2011). As miR-210 induction is a consistent feature of the hypoxia response (Corn, 2008; Huang and Zuo, 2014), it was chosen for further research as a prognostic and predictive biomarker in this study.

Blick et al. recently identified a signature of seven miRs (including miR-210) associated with low oxygen tension in bladder cancer cell lines (Blick et al, 2015). To our knowledge there is no study of the hypoxia modulation of miR-210 in bladder cancer tissue. However, there are several studies in other cancer types. Camps et al. reported a striking correlation of miR-210 levels with mortality from breast cancer (Camps et al, 2008). Gee et al. showed that high expression of miR-210 was associated with a poor prognosis in head and neck squamous cell carcinoma (Gee et al, 2010). High miR-210 expression can also have a positive prognostic impact in tumour types such as non-small cell lung cancer (Eilertsen et al, 2014) and clear cell renal cancer (McCormick et al, 2013). Nevertheless, a systematic review and meta-analysis of 16 studies of 7 cancer types, including bladder cancer found that overexpression of miR-210 was associated with poor patient survival (Wang et al, 2014).

The aim of this study was to investigate whether miR-210 expression reflects hypoxia and can be used to predict benefit from hypoxia modification in bladder cancer. It was hypothesised that as miR-210 has an important role in the transactivation of HIF-1 target genes involved in tumorigenesis, it may identify hypoxic cancer most likely to benefit from hypoxia-modifying treatment. A retrospective study was carried out to explore whether miR-210 expression predicts benefit from hypoxia modification and to compare miR-210 expression levels with data for other hypoxia markers available from other studies that used the same samples. The samples were taken from patients enrolled in the BCON phase III trial (Hoskin et al, 2010).

\section{MATERIALS AND METHODS}

Patients and tissue samples. REMARK guidelines (McShane et al, 2005) were followed throughout. A retrospective study was carried out using FFPE pre-treatment samples obtained from the BCON phase III clinical trial. Patients were diagnosed with histologically proven urothelial (transitional cell) carcinoma of the bladder stage T1-T4a (metastasis free) and randomised between November 2000 and April 2006. Samples were obtained for 251 of the 333 patients enrolled in BCON. A power calculation was performed using survival rates for bladder cancers and published effect sizes for differences between oxygenated and hypoxic tumours from the ARCON trial (Kaanders et al, 2002). The calculation assumed a 2 -year OS rate of 70\% (Hoskin et al, 2010) and CON improving survival only in patients with hypoxic tumours. Patients with oxygenated tumours having RT alone or with CON and those with hypoxic tumours having CON would have $70 \%$ survival, whilst those with hypoxic tumours having RT alone would have a $40 \%$ survival. Analysis of 150 patients would detect this difference in survival with $80 \%$ power at a significance level of 0.01 . Without bias, 183 samples were selected evenly between the two trial arms in order to fulfil the power calculation allowing for some extra.
The study was approved by the Greater Manchester Research Ethics Committee (LREC 09/H1013/24).

Patients received $55 \mathrm{~Gy}$ in 20 fractions in 4 weeks or $64 \mathrm{~Gy}$ in 32 fractions in 6.5 weeks daily, five times per week. In those randomised to the $\mathrm{CON}$ arm carbogen $\left(2 \% \mathrm{CO}_{2}\right.$ and $\left.98 \% \mathrm{O}_{2}\right)$ was administered $5 \mathrm{~min}$ before and during RT, and an oral dose of nicotinamide (40-60 $\mathrm{mg} \mathrm{kg}^{-1}$; Larkhall Laboratories, Charlbury, $\mathrm{UK})$ was given to $1 \frac{1 / 2}{2}-2 \mathrm{~h}$ before each fraction.

Histopathology. Tissue samples were obtained by pre-treatment transurethral resection of the bladder tumour (biopsy, partial or complete). Tumour debulking was performed using a diathermy loop, which produced strips of tissue approximately $6 \mathrm{~mm}$ in width and of viable length. One block per $\mathrm{cm}$ tumour diameter was FFPE. One $4 \mu \mathrm{m}$ haematoxylin and eosin-stained section from each FFPE block was analysed. Staging was both clinical and pathological (TNM AJCC/UICC classifications). Grading was according to the UK Royal College of Pathologists guidelines (WHO, 1973). miR-210 analysis was performed on samples with $\geqslant 10 \%$ viable tumour in order to include quantification of stromal miR-210.

RNA extraction and cDNA synthesis. RNA was extracted from FFPE samples (three $20 \mu \mathrm{m}$ sections) using the RecoverAll Total Nucleic Acid Isolation Kit (Life Technologies, Paisley, UK), which included DNAse I treatment. RNA purity was assessed using the $260 / 280$ ratio and all samples fell with the range of $1.8-2.1$ as recommended by the manufacturer. Additional information on RNA quality assessment is given in the Supplementary Table S1. Total RNA from each sample was reverse transcribed using TaqMan MicroRNA reverse transcription kit (Life Technologies). Preamplification of DNA involved pooled TaqMan assays (miR210 and miR-16), Preamplification Master Mix (both Life Technologies) and a PCR thermal cycler (Veriti 9902, Life Technologies). PreAmplification Master Mix was validated by the manufacturer to enrich uniformly up to 100 gene-specific targets using 1-250 ng starting material without introducing bias.

Quantitative PCR for expression of miRNA. Customised 96-well plates were pre-spotted using TaqMan assays by Life Technologies. Quantitative real-time PCR (qPCR) was conducted using the ABI Prism 7900 qPCR system as per the manufacturer's instructions. Manual Cq values were determined using the ABI Prism Sequence Detection System software (Life Technologies). Relative quantification of miR-210 expression was calculated using the $2^{-\Delta \mathrm{Cq}}$ method (Livak and Schmittgen, 2001). Expression of miR-210 was normalised to the reference gene RPL16. A priori it was decided to dicotomise patients as low miR-210 (< median) or high miR$210 \geqslant$ median) as a median cutoff had been used in other studies using mRNA hypoxia markers (Buffa et al, 2010; Eustace et al, 2013b) and miR-210 (Camps et al, 2008; Gee et al, 2010; Osugi et al, 2015). Minus reverse transcriptase controls and no template controls were analysed and had negligible Cq values ( $>38$ cycles). Brain reference control RNA (Life Technologies) was included on each plate. Gene expression was within two cycles for all repeats.

End points and statistical analyses. Analyses were performed using SPSS (IBM, version 12, Portsmouth, UK) and Prism (Graphpad, version 6, La Jolla, CA, USA). All survival analyses were conducted on an 'intention to treat' basis. Five-year OS time was taken as time from randomisation to death of any cause; patients still alive were censored to date of last follow-up or at 5 years, depending on what was earlier. Five-year local progression-free survival (LPFS) was taken as time to tumour recurrence in bladder, locoregional failure or death from any cause. Patients with persistent muscle-invasive disease or with no cystoscopy post treatment had their time set to zero. Survival estimates were performed using the Kaplan-Meier method and differences compared using the Mantel-Cox log-rank test. Hazard ratios (HRs) and 95\% CI were obtained using Cox's proportional hazard 
model. Heterogeneity in the treatment effect according to miR-210 expression was addressed within a stratified Cox regression model using appropriate stratum-specific treatment variables. The analysis was performed first just with miR-210 and treatment information and second adjusted for prognostic features. The $\chi^{2}$-test was used to compare proportions across the levels of categorical factors and Yates' correction was used for $2 \times 2$ tables; the Mann-Whitney $U$-test was used to compare median values for continuous variables between two groups. All $P$-values were twosided and agreed statistical significance was 0.05 . Data for HIF- $1 \alpha$ (Hunter et al, 2014), and CA9, Glut-1 and necrosis (Eustace et al, 2013a) were available from other studies. No corrections were made for multiple testing and should be interpreted accordingly. Analyses were carried out for OS and LPFS but as the results were very similar only the results for OS detailed in the text below (LPFS results are shown in Supplementary Figures S1, S2, S4 and S7).

\section{RESULTS}

Tumour sections from 183 patients had a median RNA yield of $88.0 \mathrm{ng}^{-1} \mathrm{l}^{-1}$ (range 1.1-502.4 $\mathrm{ng}^{-1} \mathrm{l}^{-1}$ ) and median $80 \%$ tumour $(10-100 \%)$. The samples were preamplified and miR-210 was quantified for all samples (100\% success rate). The median miR210 for the 183 patients was 0.023 (range $1.5 \times 10^{-3}-0.54$ ).

In the subset of 183 BCON patients selected for study, 97 received $\mathrm{RT}$ and 86 received RT + CON. Most patients (181; 99\%) received $\geqslant 90 \%$ of the prescribed $\mathrm{RT}$. In the experimental arm, 80 $(93 \%)$ patients received $\geqslant 90 \%$ of the stipulated carbogen doses and $63(73 \%)$ patients received $\geqslant 90 \%$ of the stipulated nicotinamide doses. All analyses were conducted on an 'intention to treat' basis. The 183 patients had a median age at randomisation of 75 (51-88) years; $146(79.8 \%)$ patients were male and $37(20.2 \%)$ patients were female. Stage was T1, T2, T3, T4a and T4b in $18(9.8 \%), 123$ (67.2\%), $35(19.1 \%), 6(2.7 \%)$ and $1(0.6 \%)$, respectively. All were $\mathrm{N} 0$ and M0. There were no statistically significant differences in clinicopathologic features between treatment arms (Supplementary Table S2). Table 1 shows the clinicopathological details in relation to $\mathrm{miR}-210$ expression.

When miR-210 expression levels were compared with data for other hypoxia markers several associations were found. Higher miR-210 expression was observed in patients with high HIF-1 $\alpha$ (Mann-Whitney $U P=0.001, n=116$ ), CA9 (Mann-Whitney $U$ $P=0.0004, n=98$ ) and Glut-1 (Mann-Whitney $U P=0.001$, $n=100$ ) protein levels. On the gene level, higher miR-210 expression was associated with a high expression of a 26-gene head and neck cancer hypoxia signature (Mann-Whitney $U$ $P=0.007, n=111)$. Presence of hypoxia-related tumour necrosis was also associated with high miR-210 expression $\left(\chi^{2} P=0.02\right.$, $n=182)$. This association was also observed with the presence of concurrent pTis $\left(\chi^{2} P=0.03, n=183\right)$. Expression of miR-210 was significantly associated with per cent tumour material in the sample $\left(\chi^{2} P=0.03, n=183\right)$. Figure 1 shows the per cent distribution of miR-210 (low vs high) according to each hypoxia biomarker. Supplementary Table S3 shows the clinicopathological details per trial arm normalised to \% tumour material.

Prognosis was investigated in all 183 patients in this study. Figure 2 shows that expression of miR-210 had no prognostic significance for 5-year OS in this patient group (log-rank $P=0.74$ ). Five-year OS was $46.1 \%$ for low miR-210 (<median) and $45.7 \%$ for high $\operatorname{miR}-210 \geqslant$ median). Of the patient variables only increasing age $(P=0.004)$ was associated with a poor prognosis. Table 2 shows the HRs for 5-year OS, and accompanying $P$-values for all clinicopathological variables analysed. Supplementary Table $\mathrm{S} 4$ replicates this table using the RT cohort alone.
Table 1. Clinicopathological details by miR-210 expression

\begin{tabular}{|c|c|c|c|}
\hline & $\begin{array}{l}\text { Low miR-210 } \\
\quad(n=91)\end{array}$ & $\begin{array}{l}\text { High miR-210 } \\
\quad(n=92)\end{array}$ & $P$ \\
\hline $\begin{array}{l}\text { Treatment } \\
\text { RT } \\
\text { RT + CON }\end{array}$ & $\begin{array}{l}52(57 \%) \\
39(43 \%)\end{array}$ & $\begin{array}{l}45 \text { (49\%) } \\
47 \text { (51\%) }\end{array}$ & 0.33 \\
\hline $\begin{array}{l}\text { Gender } \\
\text { Male } \\
\text { Female }\end{array}$ & $\begin{array}{l}76(84 \%) \\
15(16 \%)\end{array}$ & $\begin{array}{l}70(76 \%) \\
22(24 \%)\end{array}$ & 0.29 \\
\hline Age (years) & 75 (53-88) & $74(51-87)$ & 0.94 \\
\hline $\begin{array}{l}\text { Tumour stage } \\
\text { T1 } \\
\text { T2 } \\
\text { T3 } \\
\text { T4 }\end{array}$ & $\begin{array}{l}12(13 \%) \\
60(66 \%) \\
16(18 \%) \\
3(3 \%)\end{array}$ & $\begin{array}{l}6(6 \%) \\
63(69 \%) \\
19(21 \%) \\
4(4 \%)\end{array}$ & 0.48 \\
\hline $\begin{array}{l}\text { TURBT } \\
\text { Complete } \\
\text { Partial } \\
\text { Biopsy } \\
\text { No data }\end{array}$ & $\begin{array}{c}39(43 \%) \\
27(30 \%) \\
23(25 \%) \\
2(2 \%)\end{array}$ & $\begin{array}{c}39(43 \%) \\
27(30 \%) \\
20(22 \%) \\
6(6 \%)\end{array}$ & 0.92 \\
\hline$\%$ Tumour & $75(10-100)$ & $80(10-90)$ & 0.03 \\
\hline $\begin{array}{l}\text { Necrosis } \\
\text { Present } \\
\text { Absent } \\
\text { No data }\end{array}$ & $\begin{array}{c}38(42 \%) \\
52(57 \%) \\
1(1 \%)\end{array}$ & $\begin{array}{r}54 \\
38 \\
0\end{array}$ & 0.02 \\
\hline $\begin{array}{l}\text { Concurrent pTis } \\
\text { Present } \\
\text { Absent }\end{array}$ & $\begin{array}{l}32(35 \%) \\
59(65 \%)\end{array}$ & $\begin{array}{l}18(20 \%) \\
74(81 \%)\end{array}$ & 0.03 \\
\hline $\begin{array}{l}\mathrm{Hb}\left(\mathrm{gl}^{-1}\right) \\
\text { No data }\end{array}$ & $\begin{array}{c}13.9(9.3-17.2) \\
0(0 \%)\end{array}$ & $\begin{array}{c}13.7(9.8-17.0) \\
1(1 \%)\end{array}$ & 0.20 \\
\hline $\begin{array}{l}\text { HIF- } 1 \alpha \text { protein } \\
\text { No data }\end{array}$ & $\begin{array}{l}7.5(0-169.4) \\
37(41 \%)\end{array}$ & $\begin{array}{c}27.7(0-198.8) \\
30(33 \%)\end{array}$ & 0.001 \\
\hline $\begin{array}{l}\text { CA9 protein } \\
\text { No data }\end{array}$ & $\begin{array}{l}0(0-50.9) \\
47(52 \%)\end{array}$ & $\begin{array}{l}4.3(0-208.4) \\
38(41 \%)\end{array}$ & 0.0004 \\
\hline $\begin{array}{l}\text { Glut-1 protein } \\
\text { No data }\end{array}$ & $\begin{array}{c}73.3(0-283.8) \\
47(51 \%)\end{array}$ & $\begin{array}{c}158.8(0-300.0) \\
36(39 \%)\end{array}$ & 0.001 \\
\hline $\begin{array}{l}\text { 26-gene HS } \\
\text { No data }\end{array}$ & $\begin{array}{l}0.046(0.001-0.13) \\
37(41 \%)\end{array}$ & $\begin{array}{l}0.059(0.005-0.16) \\
35(38 \%)\end{array}$ & 0.007 \\
\hline \multicolumn{4}{|c|}{$\begin{array}{l}\text { Abbreviations: } \mathrm{CA} 9=\text { carbonic anhydrase } 9 ; \mathrm{CON}=\text { carbogen and nicotinamide; } \mathrm{Glut}-1= \\
\text { glucose transporter-1; } \mathrm{Hb}=\text { haemoglobin; } \mathrm{HS}=\text { hypoxia score; } \mathrm{pT} \text { Tis=carcinoma in situ } \\
\text { TURBT = transurethral resection of the bladder tumour. Data are represented by } n(\%) \text { or } \\
\text { median (range). }\end{array}$} \\
\hline
\end{tabular}

In the subset of BCON patients studied the benefit of adding CON to RT was not statistically significant (Figure $3 \mathrm{~A}$ ). In the 183 patients studied 5 -year OS was $43.3 \%$ in the RT arm vs $45.3 \%$ in the $\mathrm{RT}+\mathrm{CON}$ arm (log-rank $P=0.23, \mathrm{HR} 0.78,95 \%$ CI 0.52-1.16), which compares with a HR of 0.86 (95\% CI $0.74-$ 0.99 , log-rank $P=0.04$ ) in the 333 patients in the BCON trial. When stratified according to median miR-210 expression, there was a trend towards high miR-210 expression predicting benefit from hypoxia modification in patients. In patients with low miR$210(n=91)$ the 5 -year OS was $48.1 \%$ for patients receiving RT alone and $43.6 \%$ for those receiving $\mathrm{RT}+\mathrm{CON}$ (log-rank $P=0.95$, HR 1.02, 95\% CI 0.58-1.79; Figure 3B). In patients with high miR-210 $(n=92)$ the 5 -year OS was $37.8 \%$ for RT and $53.2 \%$ for $\mathrm{RT}+\mathrm{CON}$ (log-rank $P=0.07$, HR $1.68,95 \%$ CI $0.95-3.00$ ); Figure $3 \mathrm{C}$ ). The trend towards a reduced risk of death when a patient received $\mathrm{RT}+\mathrm{CON}$ compared with $\mathrm{RT}$ alone in the high miR-210 subgroup was retained in a multivariate analysis including patient age as a covariate $(P=0.07, \mathrm{HR} 1.62,95 \% \mathrm{CI}$ $0.92-2.81)$. This trend was not observed in the low-miR-210 subgroup $(P=0.96$, HR $1.03,95 \%$ CI $0.62-1.84)$. It is noteworthy that when the data are corrected for \% tumour material this trend reaches significance (log-rank $P=0.04$, HR 1.82, 95\% CI 1.02-3.23; 

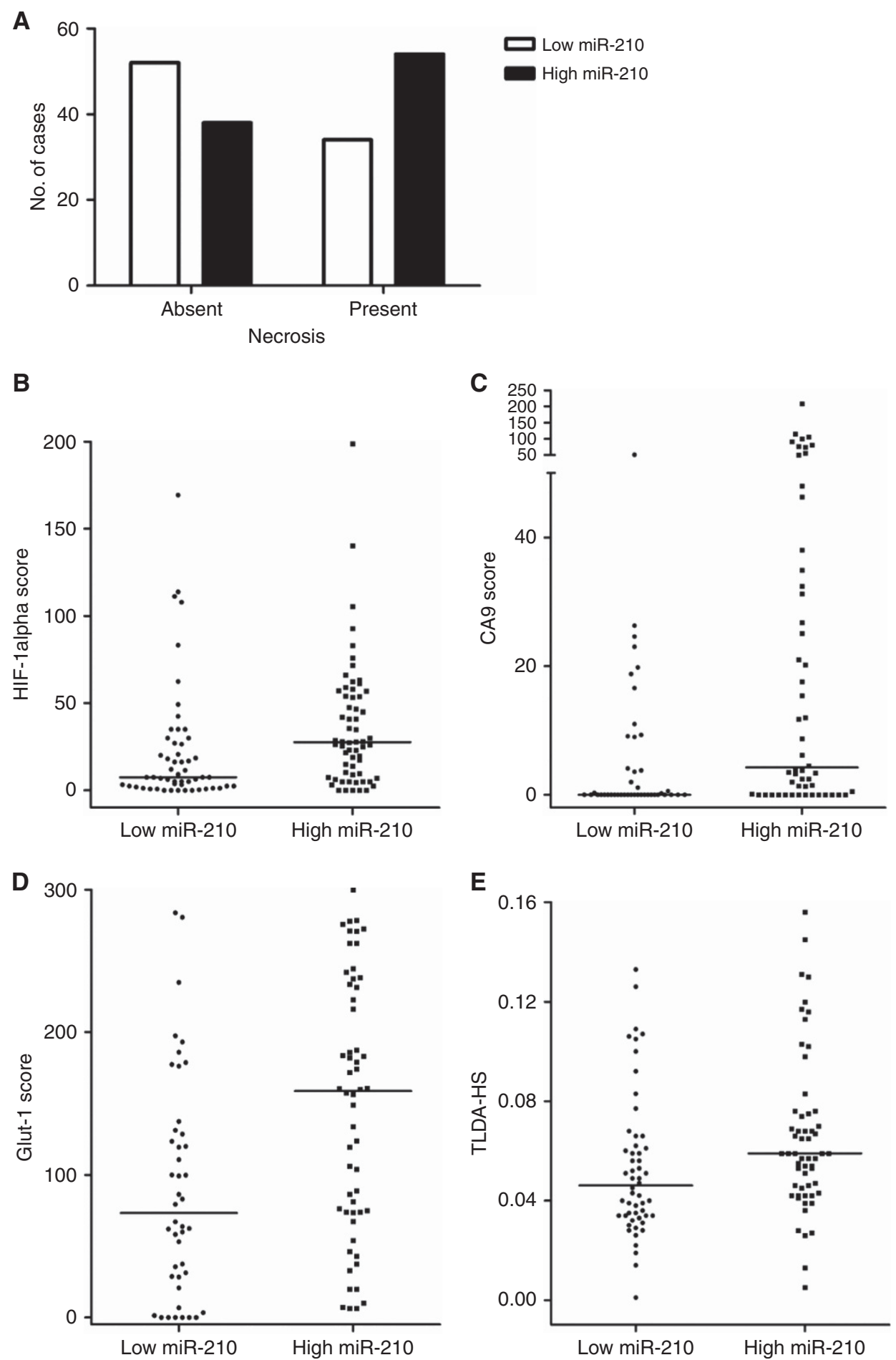

Figure 1. High miR-210 is strongly associated with markers of tumour hypoxia: (A) tumour necrosis $\left(\chi^{2} P=0.02\right) ;(B) H I F-1 \alpha$ protein (Mann-Whitney $U P=0.001$ ); (C) CA9 protein (Mann-Whitney U P=0.0004); (D) Glut-1 protein (Mann-Whitney $U P=0.001$ ); and (E) 26-gene hypoxia score (TLDAHS) (Mann-Whitney $\cup P=0.007)$. Line represents the median value.

Supplementary Figures S3 and S4). Survival analyses (OS) were repeated, including patients with samples with $\geqslant 50 \%$ viable tumour. Similar trends were seen but with reduced significance due to the smaller number of patients studied (Supplementary Figures S5 and S6).

Several hypoxia markers can predict benefit from CON. The combination of miR-210 and necrosis, the best independently performing predictor of benefit showed that patients with high miR-210 and necrosis significantly benefit from CON (5-year OS was $34.6 \%$ for RT and $59.3 \%$ for $\mathrm{RT}+\mathrm{CON}$ (log-rank $P=0.05$, HR 2.12, 95\% CI 1.00-4.51; Figure 4A). The reduced risk of death when a patient received $\mathrm{RT}+\mathrm{CON}$ compared with $\mathrm{RT}$ alone in the high miR-210 and necrosis subgroup retained significance in a multivariate analysis including patient age as a covariate $(P=0.02$, HR 2.31, 95\% CI 1.13-4.68). More interestingly, patients with low miR-210 without necrosis show a strong trend that CON treatment may not be suitable (5-year OS was $55.3 \%$ for RT and $24.3 \%$ for $\mathrm{RT}+\mathrm{CON}$, log-rank $P=0.08$, HR $0.51,95 \%$ CI $0.24-1.09$; 


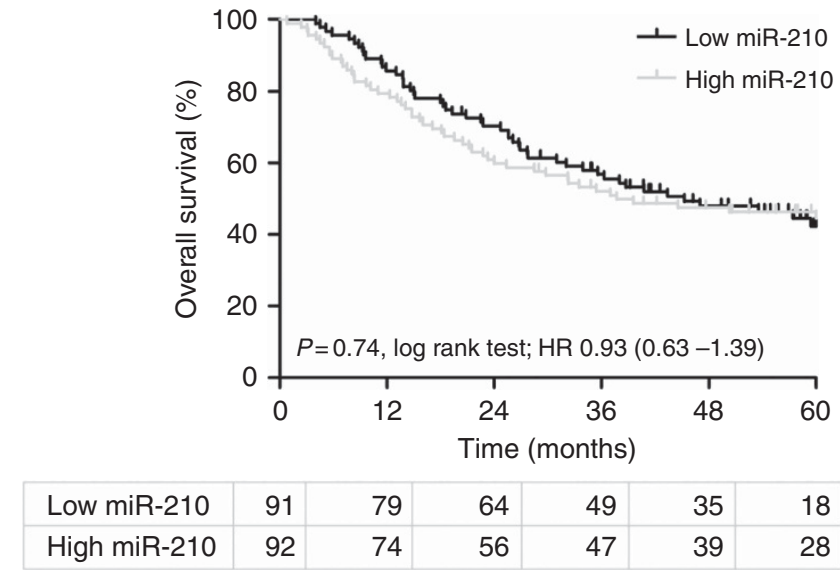

Figure 2. Kaplan-Meier plot for overall survival according to miR-210 expression in all BCON patients $(n=183)$. Log-rank $P$, hazard ratios $(\mathrm{HR})$ and numbers at risk in each yearly interval are also shown.

Figure 4B). The age-adjusted $\mathrm{HR}$ is $0.53(P=0.10,95 \% \mathrm{CI}$ $0.25-1.14)$.

Five-year LPFS results also show this pattern with significant log-rank results being achieved for both patient populations (high miR-210 plus necrosis $P=0.02$ and low miR-210 without necrosis $P=0.05$; Supplementary Figure S7). The reduced risk of death when a patient received RT $+\mathrm{CON}$ compared with RT alone in the high miR-210 and necrosis subgroup retained significance after multivariate analysis $(P=0.01$, HR $2.59,95 \%$ CI $1.26-5.32$ vs $P=0.06$, HR $0.50,95 \%$ CI $0.24-1.05$ for patients in the low miR210 without necrosis).

\section{CONCLUSIONS}

Tumour hypoxia is associated with poor survival outcomes in bladder cancer (Hoskin et al, 2003; Theodoropoulos et al, 2004; Palit et al, 2005; Ord et al, 2007; Eustace et al, 2013a; Hunter et al, 2014). Tumour hypoxia modification has shown some success in bladder cancer patients treated with RT. The BCON trial showed significant improvements in OS, risk of death and local relapse for bladder cancer patients receiving RT + CON (Hoskin et al, 2010). The results of this current study support previous findings that patients with well-oxygenated tumours do not benefit from hypoxia-modifying interventions. In this subset of patients, alternative methods for radiosensitisation are likely to be more effective, and regimens including concurrent 5-FU and mitomycin C (James et al, 2012) or gemcitabine (Choudhury et al, 2011) should be considered. Other studies have shown that BCON patients with hypoxic tumours benefit most from hypoxiamodifying intervention (Eustace et al, 2013a; Hunter et al, 2014). We aimed to investigate whether hypoxia-associated miR-210 could improve on the predictive ability of previously studied hypoxia biomarkers. To our knowledge this is the first study of miR-210 as a surrogate marker of hypoxia in bladder cancer tissue.

Direct measurements of tumour hypoxia using an Eppendorf electrode is not feasible in bladder cancer due to tumour inaccessibility. Pimonidazole has been used as a surrogate marker of tumour hypoxia but it too is invasive and its use has not transferred into the clinic. Use of immunohistochemical markers of hypoxia such as HIF- $1 \alpha$, CA9 and Glut-1 is very attractive owing to the availability of FFPE material. However, accurate quantification can suffer from analyst subjectivity and sampling bias/tumour heterogeneity. Recent studies have shown the potential of gene signatures to dichotomise head and neck cancer samples according

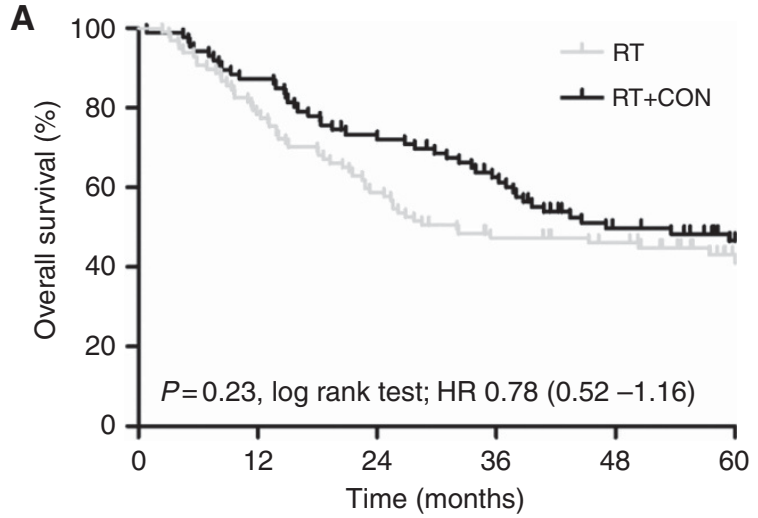

\begin{tabular}{|l|l|l|l|l|l|l|}
\hline RT & 97 & 77 & 58 & 44 & 38 & 21 \\
\hline RT+CON & 86 & 76 & 62 & 53 & 36 & 25 \\
\hline
\end{tabular}

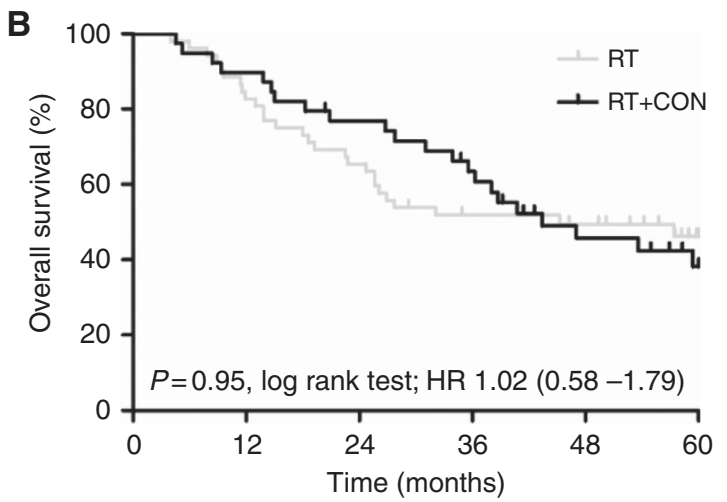

\begin{tabular}{|l|l|l|l|l|l|l|}
\hline RT & 52 & 44 & 35 & 26 & 21 & 9 \\
\hline RT+CON & 39 & 36 & 30 & 25 & 15 & 9 \\
\hline
\end{tabular}

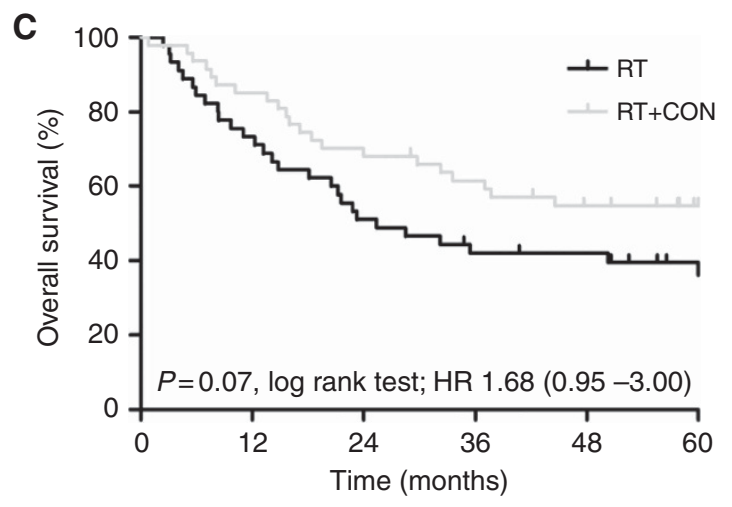

\begin{tabular}{|l|r|r|r|r|r|r|}
\hline RT & 45 & 34 & 24 & 19 & 18 & 12 \\
\hline RT+CON & 47 & 41 & 33 & 29 & 23 & 16 \\
\hline
\end{tabular}

Figure 3. Kaplan-Meier plots for overall survival after radiotherapy (RT) or radiotherapy plus carbogen and nicotinamide (RT + CON) (A) without further stratification $(n=183)$ and stratified according to (B) low miR-210 or (C) high miR-210 expression. Log-rank P-values, hazard ratios (HR) and number of patients at risk in each yearly interval are also shown.

to oxygen status (Eustace et al, 2013b) but measurement of mRNA can be limited by its intrinsic instability and presence of RNAses within the cell despite FFPE processing. miRs are more stable than mRNAs and less vulnerable to deterioration in FFPE (Hall et al, 2012). We have shown that miR-210 is significantly associated with all hypoxia-related markers available for analysis; HIF-1 $\alpha$, CA9, 
A

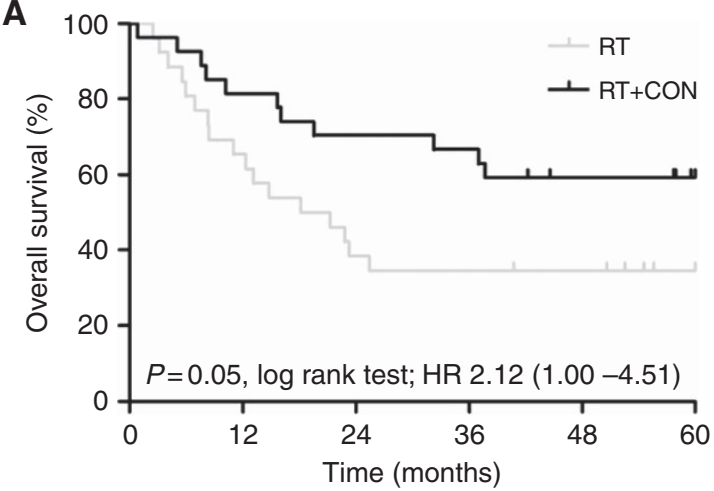

\begin{tabular}{|l|r|r|r|r|r|r|r|}
\hline $\mathrm{RT}$ & 26 & 18 & 11 & 10 & 9 & 4 \\
\hline $\mathrm{RT}+\mathrm{CON}$ & 27 & 23 & 20 & 19 & 15 & 11 \\
\hline
\end{tabular}

B

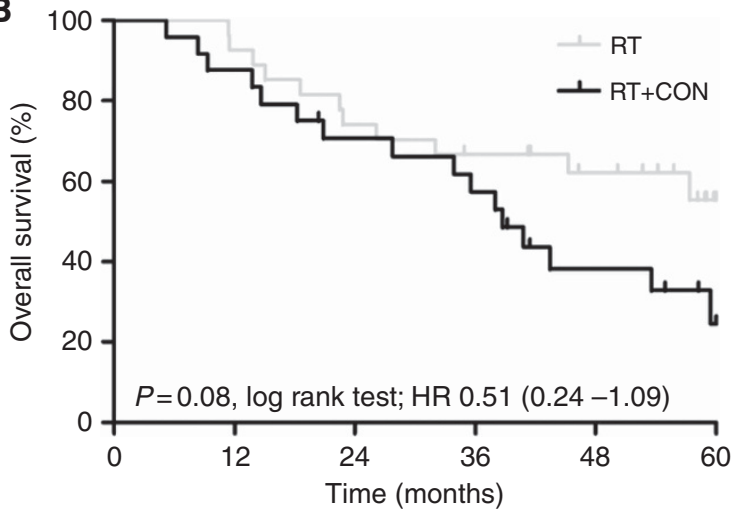

\begin{tabular}{|l|r|r|r|r|r|r|r|}
\hline$R T$ & 27 & 26 & 21 & 18 & 14 & 4 \\
\hline$R T+C O N$ & 24 & 22 & 17 & 15 & 8 & 3 \\
\hline
\end{tabular}

Figure 4. Kaplan-Meier plots for overall survival after radiotherapy (RT) or radiotherapy plus carbogen and nicotinamide $(R T+C O N)$ in patients with (A) high miR-210 and necrosis present and (B) low miR-210 and necrosis absent. Log-rank $P$, hazard ratios (HR) and numbers at risk in each yearly interval are also shown.

Glut-1, tumour necrosis and expression of a 26-gene head and neck signature.

This study also supports the theory that miR-210 promotes the stabilisation of HIF- $1 \alpha$ and their expression is interdependent (Chang et al, 2013; Wang et al, 2014). In hypoxia, miR-210 levels increase in response to binding the HIF-1 $\alpha$ to the hypoxia responsive element in its promoter region (Corn, 2008), in addition to an increase in nascent primary transcript (pri-miR-210) (Zhang et al, 2009). miR-210 also promotes the stabilisation of HIF- $1 \alpha$ as a part of a positive feedback loop (Chang et al, 2013; Wang et al, 2014), and its presence is dependent on the level of HIF-1 $\alpha$. Future biochemical studies may be able to demonstrate the in situ colocalisation of miR-210 and HIF- $1 \alpha$ in bladder cancer tissue, but this was beyond the scope of this current biomarker study.

miR-210 may be able to stratify patients according to tumour hypoxia and predict benefit from hypoxia modification. There was an improvement in 5-year OS in patients receiving $\mathrm{RT}+\mathrm{CON}$ compared with RT alone in patients with high miR-210 expression with a significance level of 0.07 following multivariate Cox regression. This difference in treatment success was not observed in patients with low miR-210 expression. It is possible that analysis using a larger cohort of patients may have improved significance levels as our power calculation stipulated 150 patients were required to detect a significant difference in $\mathrm{HR}$ with $P=0.01$ and $80 \%$ power. However, miR-210 performed less well than other
Table 2. Hazard ratios for 5-year overall survival in all patients

\begin{tabular}{|c|c|c|c|c|}
\hline & $N$ & HR & $95 \% \mathrm{Cl}$ & $P$ \\
\hline $\begin{array}{l}\text { Treatment } \\
\text { RT } \\
\text { RT }+ \text { CON }\end{array}$ & 183 & 1.27 & $0.86-1.89$ & 0.23 \\
\hline $\begin{array}{l}\text { Gender } \\
\text { Male } \\
\text { Female }\end{array}$ & 183 & 0.95 & $0.58-1.56$ & 0.83 \\
\hline Median age (years) & 183 & 0.56 & $0.38-0.83$ & 0.004 \\
\hline $\begin{array}{c}\text { Stage } \\
\text { T1-2 } \\
\text { T3-4a }\end{array}$ & 183 & 1.30 & $0.81-2.08$ & 0.28 \\
\hline $\begin{array}{l}\text { TURBT } \\
\text { Complete } \\
\text { Partial/biopsy }\end{array}$ & 176 & 1.20 & $0.80-1.80$ & 0.38 \\
\hline $\begin{array}{c}\text { Necrosis } \\
\text { Absent } \\
\text { Present }\end{array}$ & 182 & 0.95 & $0.64-1.42$ & 0.82 \\
\hline $\begin{array}{l}\text { pTis } \\
\text { Absent } \\
\text { Present }\end{array}$ & 183 & 1.32 & $0.84-2.09$ & 0.23 \\
\hline Median $\mathrm{Hb}\left(g \mathrm{I}^{-1}\right)$ & 182 & 1.10 & $0.74-1.63$ & 0.63 \\
\hline Median miR-210 & 183 & 0.93 & $0.63-1.39$ & 0.74 \\
\hline
\end{tabular}

hypoxia markers. Previously, we showed that necrosis, HIF- $1 \alpha$ and CA9 but not Glut-1 or a 26-gene head and neck signature predicted benefit from the addition of CON to RT in patients with bladder cancer (Eustace et al, 2013a, b; Hunter et al, 2014). The most predictive markers, and perhaps the best ones for further study, were necrosis, HIF- $1 \alpha$ and CA9.

When exploring the possibility of combining miR-210 with other hypoxia markers we revealed a significant treatment interaction when miR-210 was combined with necrosis. Patients with a hypoxic tumour were significantly less likely to benefit from CON than patients treated with RT alone. The source of this treatment interaction is unclear, but infers that there is optimal tumour oxygenation status for this treatment type.

In the study reported here miR-210 was not prognostic for OS or LPFS in bladder cancer. A recent systemic review and metaanalysis including 1809 patients suggested that miR-210 had a limited ability as a prognostic factor for OS in several different cancer types including breast and renal cancers (Wang et al, 2014). This is consistent with previous findings that HIF- $1 \alpha$, CA9 and Glut-1 are not prognostic in BCON patients (Hunter et al, 2014), but contradicts results of other studies (Hoskin et al, 2003; Palit et al, 2005; Ord et al, 2007; Eustace et al, 2013a). These discrepancies may be due to differences in analytical techniques and sample sizes.

This is the first study to use miR-210 as a biomarker of hypoxia using bladder cancer tissue samples. The results show some potential for miR-210 in this role and support its further examination in an independent cohort of bladder cancer patients using a larger sample size and possibly using a panel of miRs. The median cutoff for miR210 expression was selected as other authors showed it discriminates patient prognosis (Camps et al, 2008; Gee et al, 2010; Osugi et al, 2015). However, a limitation of this method is that this value is not immediately transferrable between different laboratory sites. In a prospective clinical trial, an initial cohort of patients would need to be analysed to determine the median miR-210 score for subsequent patient classification. Measurement of miR-210 is a simple procedure and most hospital pathology laboratories are equipped to conduct routine qPCR analyses. Use of a clinical test could potentially assist in 
providing a more personalised treatment plan for patients with bladder cancer. With almost 430000 new cases diagnosed worldwide in 2012, bladder cancer represents the world's ninth most common cancer (World Cancer Research Fund International, 2014). Use of this biomarker could assist the clinical decision-making process and provide treatment alternatives for patients with hypoxic bladder tumours.

\section{ACKNOWLEDGEMENTS}

This work was supported by the Medical Research Council (G0801525), Cancer Research UK (C2094/A11365) and Experimental Cancer Medicine Centre funding (C1467/A7286). We thank Helen Valentine for support with the collection and storage of the bladder cancer samples, and Ric Swindell for performing statistical analyses.

\section{CONFLICT OF INTEREST}

The authors declare no conflict of interest.

\section{AUTHOR CONTRIBUTIONS}

JJI-J carried out the miR-210 work and contributed to the writing of the paper and analyses; $\mathrm{AE}$ wrote the paper and performed analyses; CMLW supervised the project; HD carried out the pathological assessments. All authors read the paper and provided feedback.

\section{REFERENCES}

Babar IA, Czochor J, Steinmetz A, Weidhaas JB, Glazer PM, Slack FJ (2011) Inhibition of hypoxia-induced miR-155 radiosensitizes hypoxic lung cancer cells. Cancer Biol Ther 12(10): 908-914.

Blick C, Ramachandran A, McCormick R, Wigfield S, Cranston D, Catto J, Harris AL (2015) Identification of a hypoxia-regulated miRNA signature in bladder cancer and a role for miR-145 in hypoxia-dependent apoptosis. Br J Cancer 113(4): 634-644.

Bruning U, Cerone L, Neufeld Z, Fitzpatrick SF, Cheong A, Scholz CC, Simpson DA, Leonard MO, Tambuwala MM, Cummins EP, Taylor CT (2011) MicroRNA-155 promotes resolution of hypoxia-inducible factor 1alpha activity during prolonged hypoxia. Mol Cell Biol 31(19): 4087-4096.

Buffa FM, Harris AL, West CM, Miller CJ (2010) Large meta-analysis of multiple cancers reveals a common, compact and highly prognostic hypoxia metagene. Br J Cancer 102(2): 428-435.

Camps C, Buffa FM, Colella S, Moore J, Sotiriou C, Sheldon H, Harris AL, Gleadle JM, Ragoussis J (2008) hsa-miR-210 Is induced by hypoxia and is an independent prognostic factor in breast cancer. Clin Cancer Res 14(5): 1340-1348.

Chang W, Lee CY, Park JH, Park MS, Maeng LS, Yoon CS, Lee MY, Hwang KC, Chung YA (2013) Survival of hypoxic human mesenchymal stem cells is enhanced by a positive feedback loop involving miR-210 and hypoxia-inducible factor 1. J Vet Sci 14(1): 69-76.

Choudhury A, Swindell R, Logue JP, Elliott PA, Livsey JE, Wise M, Symonds P, Wylie JP, Ramani V, Sangar V, Lyons J, Bottomley I, McCaul D, Clarke NW, Kiltie AE, Cowan RA (2011) Phase II study of conformal hypofractionated radiotherapy with concurrent gemcitabine in muscle-invasive bladder cancer. J Clin Oncol 29(6): 733-738.

Corn PG (2008) Hypoxic regulation of miR-210: shrinking targets expand HIF-1's influence. Cancer Biol Ther 7(2): 265-267.

Eilertsen M, Andersen S, Al-Saad S, Richardsen E, Stenvold H, Hald SM, Al-Shibli K, Donnem T, Busund LT, Bremnes RM (2014) Positive prognostic impact of miR-210 in non-small cell lung cancer. Lung Cancer 83(2): 272-278.
Eustace A, Irlam JJ, Taylor J, Denley H, Agrawal S, Choudhury A, Ryder D, Ord JJ, Harris AL, Rojas AM, Hoskin PJ, West CM (2013a) Necrosis predicts benefit from hypoxia-modifying therapy in patients with high risk bladder cancer enrolled in a phase III randomised trial. Radiother Oncol 108(1): 40-47.

Eustace A, Mani N, Span PN, Irlam JJ, Taylor J, Betts GN, Denley H, Miller CJ, Homer JJ, Rojas AM, Hoskin PJ, Buffa FM, Harris AL, Kaanders JH, West CM (2013b) A 26-gene hypoxia signature predicts benefit from hypoxia-modifying therapy in laryngeal cancer but not bladder cancer. Clin Cancer Res 19(17): 4879-4888.

Gee HE, Camps C, Buffa FM, Patiar S, Winter SC, Betts G, Homer J, Corbridge R, Cox G, West CM, Ragoussis J, Harris AL (2010) hsa-mir-210 is a marker of tumor hypoxia and a prognostic factor in head and neck cancer. Cancer 116(9): 2148-2158.

Hall JS, Taylor J, Valentine HR, Irlam JJ, Eustace A, Hoskin PJ, Miller CJ, West CM (2012) Enhanced stability of microRNA expression facilitates classification of FFPE tumour samples exhibiting near total mRNA degradation. Br J Cancer 107(4): 684-694.

Hoskin PJ, Rojas AM, Bentzen SM, Saunders MI (2010) Radiotherapy with concurrent carbogen and nicotinamide in bladder carcinoma. J Clin Oncol 28(33): 4912-4918.

Hoskin PJ, Sibtain A, Daley FM, Wilson GD (2003) GLUT1 and CAIX as intrinsic markers of hypoxia in bladder cancer: relationship with vascularity and proliferation as predictors of outcome of ARCON. Br J Cancer 89(7): 1290-1297.

Huang X, Ding L, Bennewith KL, Tong RT, Welford SM, Ang KK, Story M, Le QT, Giaccia AJ (2009) Hypoxia-inducible mir-210 regulates normoxic gene expression involved in tumor initiation. Mol Cell 35(6): 856-867.

Huang X, Zuo J (2014) Emerging roles of miR-210 and other non-coding RNAs in the hypoxic response. Acta Biochim Biophys Sin (Shanghai) 46(3): 220-232.

Hunter BA, Eustace A, Irlam JJ, Valentine HR, Denley H, Oguejiofor KK, Swindell R, Hoskin PJ, Choudhury A, West CM (2014) Expression of hypoxia-inducible factor-1alpha predicts benefit from hypoxia modification in invasive bladder cancer. Br J Cancer 111(3): 437-443.

James ND, Hussain SA, Hall E, Jenkins P, Tremlett J, Rawlings C, Crundwell M, Sizer B, Sreenivasan T, Hendron C, Lewis R, Waters R, Huddart RA (2012) Radiotherapy with or without chemotherapy in muscle-invasive bladder cancer. N Engl J Med 366(16): 1477-1488.

Kaanders JH, Pop LA, Marres HA, Bruaset I, van den Hoogen FJ, Merkx MA, van der Kogel AJ (2002) ARCON: experience in 215 patients with advanced head-and-neck cancer. Int J Radiat Oncol Biol Phys 52(3): 769-778.

Kim HJ, Fay MP, Feuer EJ, Midthune DN (2000) Permutation tests for joinpoint regression with applications to cancer rates. Stat Med 19(3): 335-351.

Livak KJ, Schmittgen TD (2001) Analysis of relative gene expression data using real-time quantitative PCR and the 2(-Delta Delta C(T)) Method. Methods 25(4): 402-408.

McCormick RI, Blick C, Ragoussis J, Schoedel J, Mole DR, Young AC, Selby PJ, Banks RE, Harris AL (2013) miR-210 is a target of hypoxiainducible factors 1 and 2 in renal cancer, regulates ISCU and correlates with good prognosis. Br J Cancer 108(5): 1133-1142.

McShane LM, Altman DG, Sauerbrei W, Taube SE, Gion M, Clark GM (2005) Reporting recommendations for tumor marker prognostic studies (REMARK). J Natl Cancer Inst 97(16): 1180-1184.

Ord JJ, Agrawal S, Thamboo TP, Roberts I, Campo L, Turley H, Han C, Fawcett DW, Kulkarni RP, Cranston D, Harris AL (2007) An investigation into the prognostic significance of necrosis and hypoxia in high grade and invasive bladder cancer. J Urol 178(2): 677-682.

Osugi J, Kimura Y, Owada Y, Inoue T, Watanabe Y, Yamaura T, Fukuhara M, Muto S, Okabe N, Matsumura Y, Hasegawa T, Yonechi A, Hoshino M, Higuchi M, Shio Y, Suzuki H, Gotoh M (2015) Prognostic impact of hypoxia-inducible miRNA-210 in patients with lung adenocarcinoma. J Oncol 2015: 316745.

Palit V, Phillips RM, Puri R, Shah T, Bibby MC (2005) Expression of HIF-1alpha and Glut-1 in human bladder cancer. Oncol Rep 14(4): 909-913.

Theodoropoulos VE, Lazaris A, Sofras F, Gerzelis I, Tsoukala V, Ghikonti I, Manikas K, Kastriotis I (2004) Hypoxia-inducible factor 1 alpha expression correlates with angiogenesis and unfavorable prognosis in bladder cancer. Eur Urol 46(2): 200-208. 
Wang J, Zhao J, Shi M, Ding Y, Sun H, Yuan F, Zou Z (2014) Elevated expression of miR-210 predicts poor survival of cancer patients: a systematic review and meta-analysis. PLoS One 9(2): e89223.

World Cancer Research Fund International (2014) Bladder Cancer Statistics Vol. 2016.

WHO (1973) Histological Typing of Urinary Bladder Tumours. World Health Organization: Geneva.

Zhang Z, Sun H, Dai H, Walsh RM, Imakura M, Schelter J, Burchard J, Dai X, Chang AN, Diaz RL, Marszalek JR, Bartz SR, Carleton M, Cleary
MA, Linsley PS, Grandori C (2009) MicroRNA miR-210 modulates cellular response to hypoxia through the MYC antagonist MNT. Cell Cycle 8(17): 2756-2768.

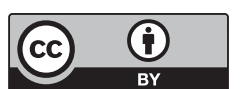

This work is licensed under the Creative Commons Attribution 4.0 International License. To view a copy of this license, visit http://creativecommons.org/licenses/by/4.0/

Supplementary Information accompanies this paper on British Journal of Cancer website (http://www.nature.com/bjc) 